\title{
Retinal Ganglion Cell Layer Thickness And Volume Measured By Optical Coherence Tomography Changes With Age, Sex, And Axial Length In A Healthy Population
}

Abbas Al-Hawasi ( $\sim$ dr.gorgah@hotmail.com )

Linköping University

Neil Lagali

Linköping University

\section{Research Article}

Keywords: Ganglion cell layer (GCL), Retinal ganglion cell layer (RGCL), Ganglion cell layer thickness (GCLT), Optical coherence tomography (OCT), ganglion cell volume (GCV)

Posted Date: February 14th, 2022

DOI: https://doi.org/10.21203/rs.3.rs-1294930/v1

License: (c) (1) This work is licensed under a Creative Commons Attribution 4.0 International License. Read Full License 


\section{Abstract}

Background: The GCL measurements with OCT are important for both ophthalmologists and neurologist because of the association with many ophthalmic and neurological diseases. Different factors can affect these measurements, as brain pathologies, ocular AL as well as age and sex. Studies that conducted to measure GCL have overlooked many of these factors. The purpose of this study is to examine the effect of age, sex, and axial length on normal retinal GCL thickness and volume in a healthy population without any neurological diseases.

Methods: A prospective cross-sectional study to measure the retinal (GCL) thickness and total volume with optical coherence tomography (OCT) with automated segmentation and manual correction where needed. Visual acuity, axial length, and autorefraction were also measured. A mixed linear model was used to determine the association of the effect of the various parameters on the GCL thickness and volume.

Results: 116 eyes of 60 subjects (12-76 years of age, $55 \%$ female) were examined of which $77 \%$ had $0 \pm 2$ D of spherical equivalent, and mean axial length was $23.86 \mathrm{~mm}$. About $25 \%$ of the OCT-automated GCL measurements required manual correction. GCL thickness did not differ in similar anatomic regions in right and left eyes $(P>0.05)$. GCL volume was greater in males relative to females after adjustment for age and axial length $(1.13 \pm 0.07 \mathrm{~mm} 3$ for male vs $1.09 \pm 0.09 \mathrm{~mm} 3$ for females; $P=0.031)$. GCL thickness differed between males and females in the inner retinal ring $(P=0.025)$ but not in the outer ring $(P=0.66)$. GCL volume declined with age $(P=0.031)$ but not after adjustment for sex and axial length $(P=0.138)$. $G C L$ volume declined with longer axial length after adjustment for age and sex $(P=0.048)$.

Conclusion: Age, sex and axial length should be taken into consideration when measuring the GCL thickness and volume with OCT. Automated OCT segmentation should be reviewed for manual adjustments.

\section{Background:}

The ganglion cell is the first order neuron in the visual pathway, with the cell body located in the retinal ganglion cell layer (GCL) while the retinal nerve fiber layer (RNFL) represents the axon of these neurons that leaves the eye and enters the brain through the optic nerve, where it synapses at the lateral geniculate body.

This anatomical separation makes it possible to study the retinal ganglion cells by direct imaging using optical coherence tomography (OCT) and consider it as a window into different physiological and pathological processes in the brain (1-6). The measurement of the RNFL has been thoroughly investigated in different diseases such as glaucoma (7), idiopathic intracranial hypertension (IIH) (8) and optic neuritis (9); on the other hand, the GCL has also been measured and investigated as the retinal ganglion cell complex (GCC), which includes both the ganglion cell layer and the inner plexiform layer (IPL) (10-12). 
With modern OCT devices it is possible to measure the GCL alone and not as a complex with the IPL. Some studies show changes in the GCL with age and sex $(13,14)$ without considering the effect of axial length, while other studies report GCL thickness changes with axial length (15). To date, however, no data is available on how the GCL changes taking all three factors in consideration. This relationship, however, is important to investigate as the potential clinical applications of GCL thickness and volume measurement continues to increase in ophthalmological as well as in neurological diseases. Correction for the effects of potential confounders on GCL parameters could be necessary in such investigations. The aim of this study was therefore to examine the GCL by OCT, and determine the variation in its thickness with age, axial length, and sex in a healthy population.

\section{Method And Materials:}

\section{Subjects and recruitment}

A prospective cross-sectional cohort study was conducted at the Department of Ophthalmology, Linköping University Hospital after obtaining approval of the Linköping Regional Ethics Committee (Approval no. 2015/151-31). Participants were recruited from a population of visitors to the ophthalmology department and their relatives. All participants older than 13 years of age completed a signed consent form, while younger subjects required the approval of both parents prior to enrolment in the study. Participants fulfilling any of the following criteria were excluded from the study: any ocular diseases other than mild cataract, history of ocular trauma, diabetes mellitus, any history of cardiovascular disease, carotid artery disease or cerebrovascular accident (CVA), history of radiotherapy to the face and neck, history of chemotherapy, any neurological disease or family history of such disease (eg. multiple sclerosis), or previous treatment with Ethambutol. Any abnormalities or diseases found during the study were managed according to standard clinical guidelines and the subject was excluded from the study. Recruitment of study subjects occurred during the period October 2015 - January 2019.

\section{Ophthalmic measurements}

Subjects with suspected thinning in the optic nerve head RNFL were examined by IOP and Humphrey visual field 24-2 SITA-fast to exclude glaucoma. The visual acuity, axial length, autorefraction/spectacles power, and OCT examination was performed by an expert ophthalmic nurse or ophthalmologist. Visual acuity was measured using the Snellen chart at five meters, and results were noted in decimals. Autorefraction and keratometry were measured using the Topcon ${ }^{\circledR}$ TRK-2P autorefractor-keratometer. The axial length was measured using the Carl Zeiss ${ }^{\circledR}$ IOL master 700.

The Heidelberg SPECTRALIS OCT system (Heidelberg Engineering, Germany) was used to examine and measure the retinal layers. The keratometry measurement was entered into the OCT examination protocol, and refractive error was included from the most recent spherical equivalent reading prior to OCT examination. 
The Retina dens 30x20 degrees program centered on the macula was used. The glaucoma RNFL centered on the optic nerve was examined to identify possible cases of glaucoma. By using the built-in software, the segmentation of different retinal layers was made, and any automated errors in measuring the GCL layer were corrected manually by an experienced clinician. Measurements of different anatomic sectors of the retina were made according to the scheme illustrated in Figure 1

Statistical analysis:

All data was inputted into an Excel file on a PC, after which data was de-identified and transformed into an SPSS compatible format. For each anatomic retinal sector, a paired t-test was used to compare similar sectors in both eyes. A mixed linear regression model was used for paired-eye analysis and to adjust for axial length, sex and age. Pearson correlation was used to assess volume changes with age for male and female subpopulations. All statistics were performed using IBM SPSS Statistics, Version 27.0. Armonk, NY: IBM Corp. A two-sided critical P-value of $<0.05$ indicated significance.

\section{Results:}

Data were obtained from 116 eyes of 60 subjects with a mean age of 40.2 years (range 12-76 years). $77 \%$ of eyes had a spherical equivalent (SE) refraction of $0 \pm 2$ diopters (D), while the mean axial length for the study population was $23.86 \mathrm{~mm}$ (range $22.91-26.82 \mathrm{~mm}$ ). The demographic characteristics of the study participants are summarized in Table 1.

Table -1- The demographic characteristics of the study participants 


\begin{tabular}{|c|c|c|c|c|c|c|}
\hline & Female & & Male & & All subjects & \\
\hline Parameter & Mean \pm SD & Range & Mean \pm SD & Range & Mean \pm SD & Range \\
\hline Age & $42 \pm 17.8$ & $\begin{array}{l}15.6- \\
76.4\end{array}$ & $38.0 \pm 18.1$ & $12-69.9$ & $40.2 \pm 18$ & $\begin{array}{l}12- \\
76.4\end{array}$ \\
\hline Visual acuity & $1.1 \pm 0.2$ & $0.7-2.0$ & $1.1 \pm 0.2$ & $0.6-2.0$ & $1.1 \pm 0.2$ & $\begin{array}{l}0.6- \\
2.0\end{array}$ \\
\hline \multirow[t]{2}{*}{ Axial length } & $23.55 \pm 0.79$ & $\begin{array}{l}21.98- \\
25.14\end{array}$ & $24.26 \pm 0.96$ & $\begin{array}{l}22.91- \\
26.82\end{array}$ & $23.86 \pm 0.94$ & $\begin{array}{l}21.98- \\
26.82\end{array}$ \\
\hline & & Female & Male & $\begin{array}{l}\text { All } \\
\text { subjects }\end{array}$ & & \\
\hline \multirow[t]{2}{*}{ Number of eyes } & Right & 32 & 24 & 56 & & \\
\hline & Left & 33 & 27 & 60 & & \\
\hline \multirow[t]{4}{*}{$\begin{array}{l}\text { Spherical equivalent } \\
\text { (number of eyes) }\end{array}$} & $\begin{array}{l}0 \pm 2 \\
\text { diopters }\end{array}$ & 58 & 33 & 91 & & \\
\hline & $+2-+4$ & 4 & 4 & 8 & & \\
\hline & $-2--4$ & 3 & 11 & 14 & & \\
\hline & $-3--6$ & 0 & 3 & 3 & & \\
\hline
\end{tabular}

About $25 \%$ of the GCL measurements taken by the OCT needed manual correction at some point. The GCL thickness across various retinal regions and sectors for both men and women are shown in Table 2. The thickest sectors in both male and female subpopulations separately were S1, I1, N1 followed by T1 consequently, while the thinnest sector apart from $\mathrm{C}$ was the 12 . There was no significant difference in GCL thickness within a given sector between eyes of the same subject ( $P>0.05$ for all sectors).

Total GCL volume was significantly greater in males $\left(1.13 \pm 0.07 \mathrm{~mm}^{3}\right)$ than in females $(1.09 \pm 0.09$ $\left.\mathrm{mm}^{3}\right)(\mathrm{P}=0.031)$ after adjustment for both age and axial length. In addition, GCL thickness in C, SS, TT, NN and II was significantly higher in males than in females (Table 2) after adjustment for age and axial length (Table 3).

Table -2- GCL parameter values stratified by sex and by retinal sector. 


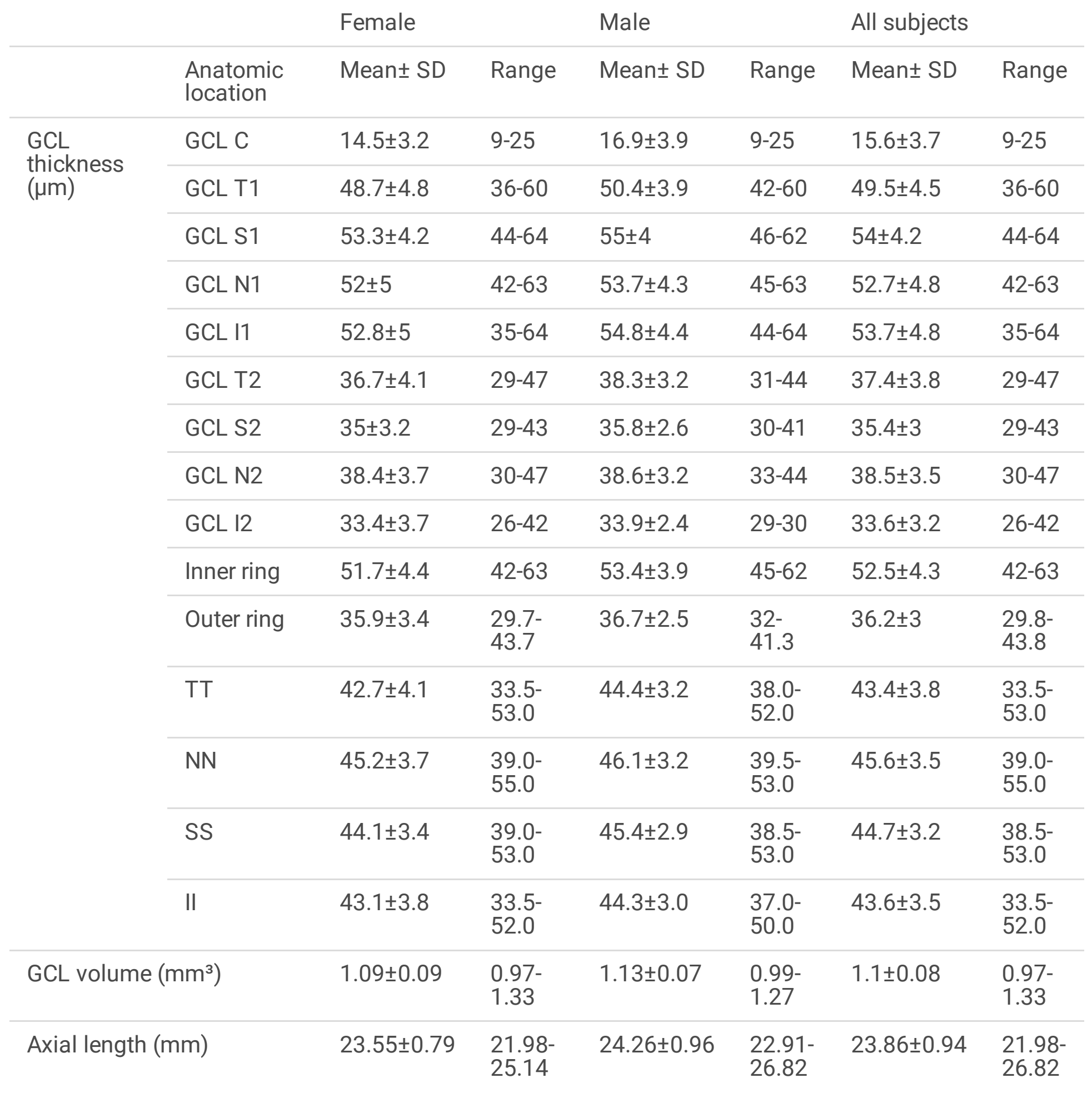

$\mathrm{N}=51$ eyes for males, 65 eyes for females; GCLV = total GCL volume; anatomic locations represent different sectors according to Figure 2; SD = standard deviation.

Table -3- Mixed linear model results (P-values) for different sectors. 


\begin{tabular}{|c|c|c|c|}
\hline Parameter & $\begin{array}{l}\text { Age, adjusted for axial } \\
\text { length and sex }\end{array}$ & $\begin{array}{l}\text { Axial length, adjusted for } \\
\text { age and Sex }\end{array}$ & $\begin{array}{l}\text { Sex, adjusted for age and } \\
\text { axial length }\end{array}$ \\
\hline GCLC & 0.603 & 0.195 & $0.000 *$ \\
\hline GCLT1 & $0.041^{\star}$ & 0.508 & 0.052 \\
\hline GCLS1 & 0.367 & 0.078 & $0.011^{*}$ \\
\hline GCLN1 & 0.504 & 0.175 & $0.032^{*}$ \\
\hline GCLI1 & 0.296 & 0.334 & $0.027 *$ \\
\hline GCLT2 & 0.059 & 0.174 & $0.018^{*}$ \\
\hline GCLS2 & 0.397 & 0.109 & 0.070 \\
\hline GCLN2 & 0.64 & 0.26 & 0.250 \\
\hline GCLI2 & $0.022^{*}$ & 0.116 & 0.226 \\
\hline $\begin{array}{l}\text { GCL inner } \\
\text { ring }\end{array}$ & 0.202 & 0.241 & $0.025^{\star}$ \\
\hline $\begin{array}{l}\text { GCL outer } \\
\text { ring }\end{array}$ & 0.125 & 0.6 & 0.660 \\
\hline GCLTT & $0.028^{*}$ & 0.274 & $0.017^{\star}$ \\
\hline GCLSS & 0.325 & 0.058 & $0.012^{\star}$ \\
\hline GCLNN & 0.493 & $0.043^{*}$ & $0.043^{*}$ \\
\hline GCLII & 0.081 & 0.171 & $0.039 *$ \\
\hline $\begin{array}{l}\text { Total GCL } \\
\text { Volume }\end{array}$ & 0.138 & $0.048^{*}$ & $0.031 *$ \\
\hline
\end{tabular}

GCL volume did not vary with age for males (Pearson $r=0.108, P=0.45$ ); however, for females, $G C L$ volume declined with age $(r=-0.367, P=0.003)$ (Figure 2$)$.

The GCL volume was reduced in eyes with longer axial length, even after adjustment for age and sex $(\mathrm{P}=$ 0.048) (Figure 3).

The GCL volume declined with age $(P=0.031)$ in the unadjusted data, but this association was no longer significant when adjusted for axial length and $\operatorname{sex}(P=0.138)$. Mixed model results for association of all sectors and regions of the GCL measurements with age, axial length, and sex are summarized in Table 3.

\section{Discussion:}

Newer OCT devices with higher precision can measure the GCL thickness in isolation without including another layer such as the IPL, and the automated OCT segmentation is correct in most of the 
measurements. In our study, however, we found that about $25 \%$ of the measurements needed to be manually adjusted after subjective examination of the automated segmentation by the OCT device, which is has not to our knowledge, been reported in any prior study. If not corrected, automated measurements may affect the assessment of the GCL and any subsequent analyses based on this layer.

A reduction in the GCL thickness and volume with age is noted based on OCT measurements. This age dependence, however, vanished in our study when correcting for the effects of sex and axial length. Notably, two prior studies (13) and (14) reported a significant change in GCL thickness with age when adjusting for sex, but they did not measure axial length; on the other hand, in another study it was reported that GCL thickness declined with age after adjustment for axial length, but without adjusting for sex (15). Our result emphasizes the importance of taking into consideration both axial length and sex as potential confounding factors.

In our data, thinning of the GCL layer with increasing axial length can be explained by the distribution of the nearly fixed number of ganglion cells in the retina (about 0.9-1.2 million) (16) over a larger surface area in case of a longer bulb.

Also, we found that the GCL layer was thicker in men than in women (Table 2), and that in women (but not men), GCL volume reduction with age was highly significant. Similarly, reduction in the brain volume with age has been reported (17), and studies have also shown a significant volumetric difference between men and women $(18,19)$. As the ganglion cell develops from the brain, changes in thickness with both age and sex may indicate a possible association between the GCL and brain volume. The effect of sex hormones during the fetal stage or in early infancy may be implicated, as these hormones affect the neural development as well as the neuronal complexity and axonal and process formation in the brain $(18,20)$.

The GCL thickness difference we found in the various anatomic sectors of the inner ring indicates that the vertical sectors (superior and inferior) are the thickest followed by the nasal and then the temporal; this may reflect that the migration pattern of ganglion cells at the macula (21) during development, where the cells adopt a more horizontal migration direction than vertical.

A limitation of our study is the relatively small population of healthy participants examined. Although the population size was sufficient for the statistical tests we used, ideally further studies with larger groups of healthy participants would be required to confirm our findings. However, given the range of neurological diseases reported to affect the GCL thickness and/or volume $(1,4-6,9,12,22)$, it is suggested that tests to exclude such diseases may be necessary when evaluating the GCL.

In summary, we describe the GCL thickness and volume differences and variation in different anatomic sectors of the retina according to age, sex and axial length. Strengths of the study were our broad exclusion criteria, spatially-resolved anatomic measurements, adjustment for keratometry and spherical equivalent for each subject to improve OCT accuracy, as well as manual correction of automated OCT measurements. Based on our results, it is recommended that future studies examining GCL thickness or 
volume should take age, sex as well as axial length into consideration as well as the possible need for manual adjustment of automated OCT measurements.

\section{Declarations:}

Ethical approval and consent to participate:

The study approved by the Linköping Regional Ethics Committee (Approval no. 2015/151-31). All participants older than 13 years gave an informed consent of participation; for participants younger than 13 years both parents gave an informed consent for the participant.

all methods were carried out in accordance with relevant guidelines and regulations.

Consent to publication:

Not applicable.

Availability of data and materials:

The datasets generated and/or analyzed during the current study are not publicly available due to its involvement in another study now but are available from the corresponding author on reasonable request.

Competing interest:

The authors have no economic interest to declare.

Funding:

Not applicable.

Author contribution:

AA is the main author and responsible for the study design, data collection and statistical analysis, NL is the supervisor and helped with the tables, graphs, and the language review.

Acknowledgments:

The authors would like to acknowledge assistance in the statistical analysis by biostatistician Mats Fredrikson, Forum Östergötland, Östergötland County and Linköping Univeristy.

Authors information:

Abbas Al-Hawasi, MD

Division of Ophthalmology

Department of Biomedical and Clinical Sciences, Faculty of Medicine 
Linköping University, 58183 Linköping, Sweden

Email: drgorgah@hotmail.com

Neil Lagali Ph.D.

Division of Ophthalmology

Department of Biomedical and Clinical Sciences, Faculty of Medicine

Linköping University, 58183 Linköping, Sweden

Email: Neil.lagali@liu.se

\section{References:}

1. Huang-Link YM, Al-Hawasi A, Eveman I. Retrograde degeneration of visual pathway: hemimacular thinning of retinal ganglion cell layer in progressive and active multiple sclerosis. J Neurol. 2014;261(12):2453-6.

2. Bandello F, Tejerina AN, Vujosevic S, Varano M, Egan C, Sivaprasad S, et al. Retinal layer location of increased retinal thickness in eyes with subclinical and clinical macular edema in diabetes type 2 . Ophthalmic Res. 2015;54(3):112-7.

3. Akashi A, Kanamori A, Ueda K, Matsumoto Y, Yamada Y, Nakamura M. The detection of macular analysis by SD-OCT for optic chiasmal compression neuropathy and nasotemporal overlap. Invest Ophthalmol Vis Sci. 2014;55(7):4667-72.

4. Kalenderoglu A, Sevgi-Karadag A, Celik M, Egilmez OB, Han-Almis B, Ozen ME. Can the retinal ganglion cell layer (GCL) volume be a new marker to detect neurodegeneration in bipolar disorder? Compr Psychiatry. 2016;67:66-72.

5. Zimmermann HG, Knier B, Oberwahrenbrock T, Behrens J, Pfuhl C, Aly L, et al. Association of Retinal Ganglion Cell Layer Thickness With Future Disease Activity in Patients With Clinically Isolated Syndrome. JAMA Neurol. 2018;75(9):1071-9.

6. Liu YL, Hsieh YT, Chen TF, Chiou JM, Tsai MK, Chen JH, et al. Retinal ganglion cell-inner plexiform layer thickness is nonlinearly associated with cognitive impairment in the community-dwelling elderly. Alzheimers Dement (Amst). 2019;11:19-27.

7. Oli A, Joshi D. Can ganglion cell complex assessment on cirrus HD OCT aid in detection of early glaucoma? Saudi J Ophthalmol. 2015;29(3):201-4.

8. Huang-Link YM, Al-Hawasi A, Oberwahrenbrock T, Jin YP. OCT measurements of optic nerve head changes in idiopathic intracranial hypertension. Clin Neurol Neurosurg. 2015;130:122-7. 
9. Huang-Link YM, Al-Hawasi A, Lindehammar $\mathrm{H}$. Acute optic neuritis: retinal ganglion cell loss precedes retinal nerve fiber thinning. Neurol Sci. 2015;36(4):617-20.

10. Scuderi G, Fragiotta S, Scuderi L, lodice CM, Perdicchi A. Ganglion Cell Complex Analysis in Glaucoma Patients: What Can It Tell Us? Eye Brain. 2020;12:33-44.

11. Pazos M, Biarnes M, Blasco-Alberto A, Dyrda A, Luque-Fernandez MA, Gomez A, et al. SD-OCT peripapillary nerve fibre layer and ganglion cell complex parameters in glaucoma: principal component analysis. Br J Ophthalmol. 2020.

12. Noval S, Henriquez-Recine MA, Contreras I, Galdos M, Zafra B, Barrio-Barrio J, et al. Macular ganglion cell complex thinning in children with visual field defects due to central nervous system pathology. Eye (Lond). 2020;34(9):1570-6.

13. Won JY, Kim SE, Park YH. Effect of age and sex on retinal layer thickness and volume in normal eyes. Medicine (Baltimore). 2016;95(46):e5441.

14. Nieves-Moreno M, Martinez-de-la-Casa JM, Morales-Fernandez L, Sanchez-Jean R, Saenz-Frances F, Garcia-Feijoo J. Impacts of age and sex on retinal layer thicknesses measured by spectral domain optical coherence tomography with Spectralis. PLoS One. 2018;13(3):e0194169.

15. Jonas JB, Xu L, Wei WB, Pan Z, Yang H, Holbach L, et al. Retinal Thickness and Axial Length. Invest Ophthalmol Vis Sci. 2016;57(4):1791-7.

16. Esporcatte BLB, Kara-Jose AC, Melo LAS, Jr., Pinto LM, Tavares IM. The Estimates of Retinal Ganglion Cell Counts Performed Better than Isolated Structure and Functional Tests for Glaucoma Diagnosis. J Ophthalmol. 2017;2017:2724312.

17. Peters R. Ageing and the brain. Postgrad Med J. 2006;82(964):84-8.

18. Schwarz JM, McCarthy MM. Steroid-induced sexual differentiation of the developing brain: multiple pathways, one goal. J Neurochem. 2008;105(5):1561-72.

19. Ruigrok AN, Salimi-Khorshidi G, Lai MC, Baron-Cohen S, Lombardo MV, Tait RJ, et al. A meta-analysis of sex differences in human brain structure. Neurosci Biobehav Rev. 2014;39:34-50.

20. Amateau SK, Alt JJ, Stamps CL, McCarthy MM. Brain estradiol content in newborn rats: sex differences, regional heterogeneity, and possible de novo synthesis by the female telencephalon. Endocrinology. 2004;145(6):2906-17.

21. Lee H, Purohit R, Patel A, Papageorgiou E, Sheth V, Maconachie G, et al. In Vivo Foveal Development Using Optical Coherence Tomography. Invest Ophthalmol Vis Sci. 2015;56(8):4537-45. 
22. Huang-Link YM, Fredrikson M, Link H. Benign Multiple Sclerosis is Associated with Reduced Thinning of the Retinal Nerve Fiber and Ganglion Cell Layers in Non-Optic-Neuritis Eyes. J Clin Neurol. 2015;11(3):241-7.

\section{Figures}

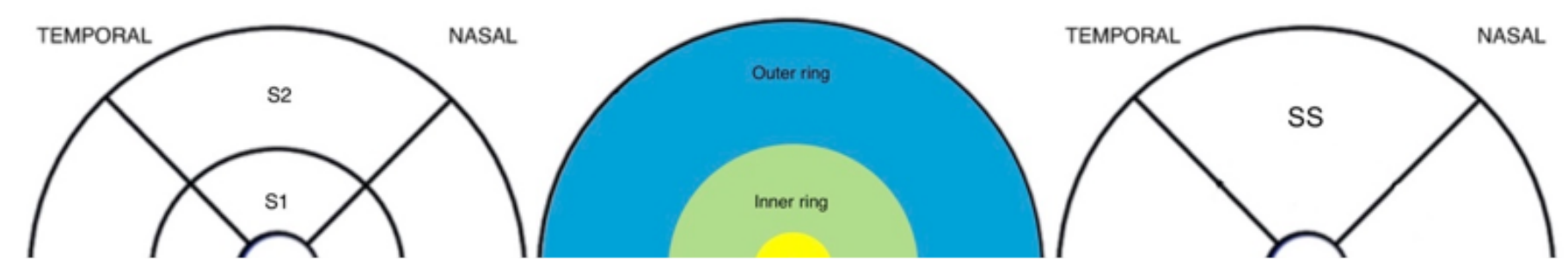

\section{Figure 1}

Division of retinal measurements into different anatomic sectors: $\mathrm{C}$ (central $1 \mathrm{~mm}$ diameter ring), $\mathrm{S}$ (superior), $\mathrm{T}$ (temporal), $\mathrm{N}$ (nasal) and I (inferior), inner ring ( $3 \mathrm{~mm}$ diameter) and outer ring $(6 \mathrm{~mm}$ diameter) SS (mean superior) TT (mean temporal) NN (mean nasal) II (mean inferior). 


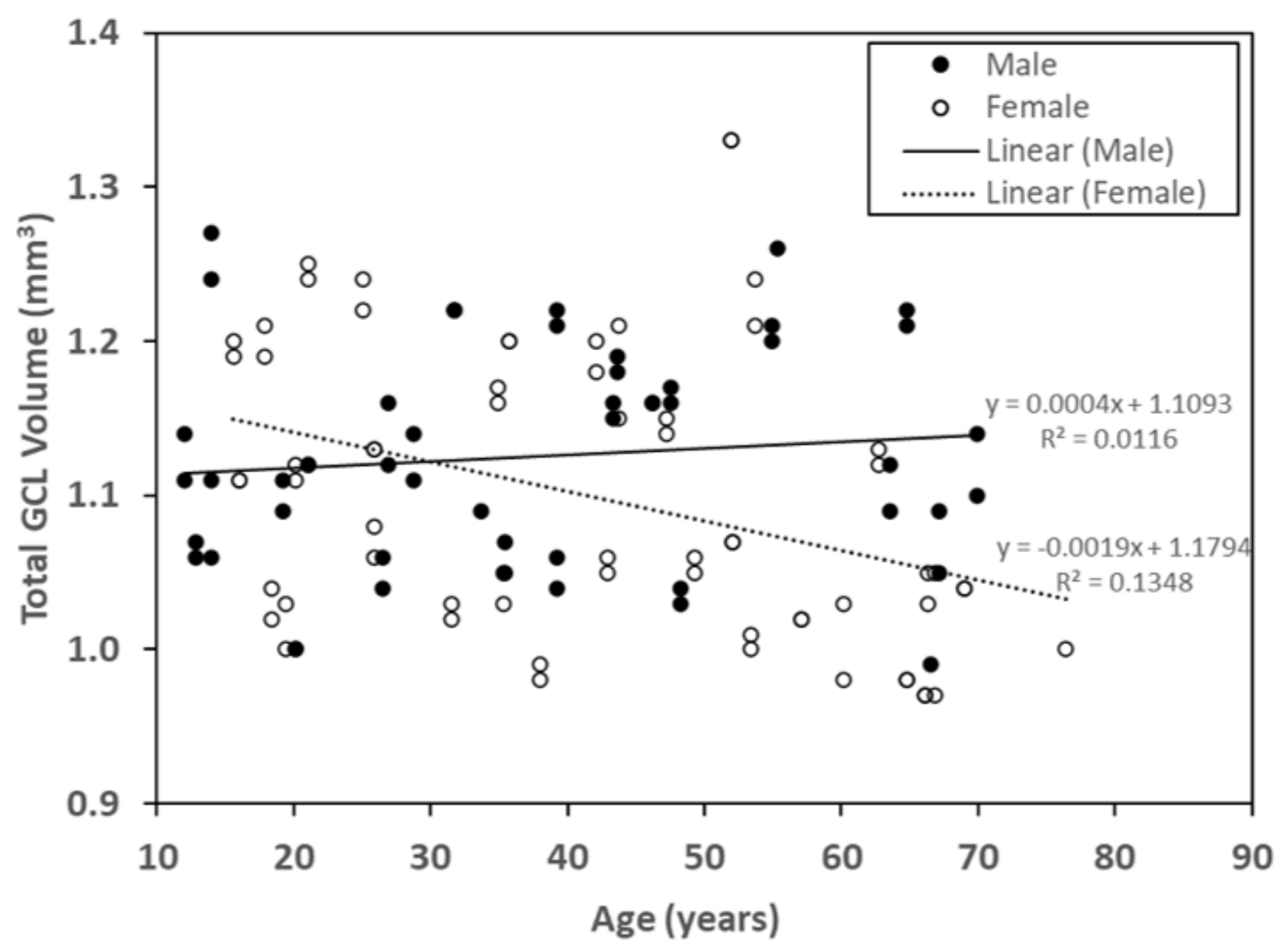

Figure 2

Variation of total GCL volume with age in the entire study population, stratified by sex. Each data point represents a single eye. The regression line and equations are shown. After adjustment for axial length and sex, total GCL volume did not have an age association ( $P=0.138)$; however, the association with age differed for females and males, being significant for females only $(P=0.003)$. 


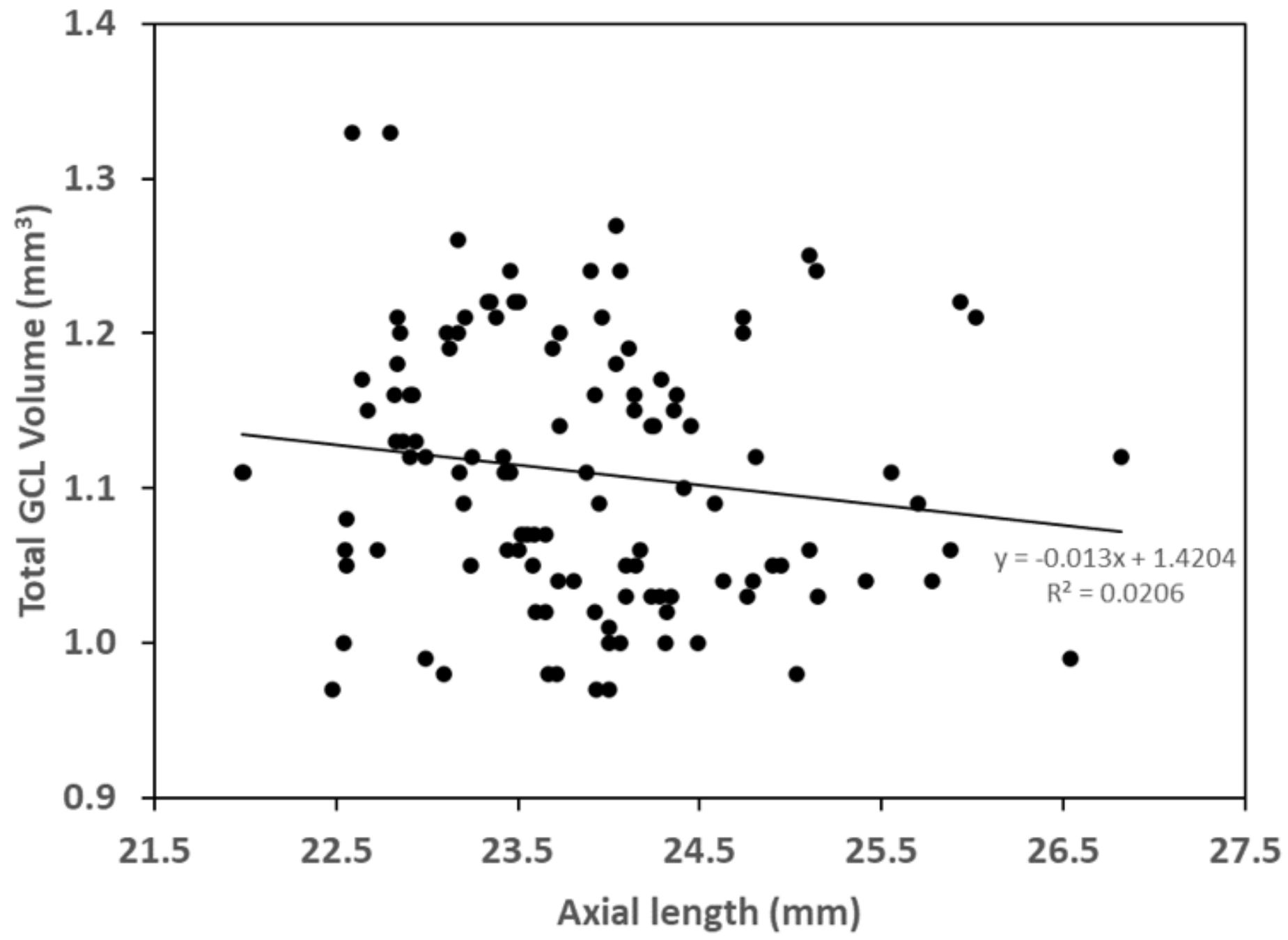

Figure 3

Variation of total GCL volume with axial length in the entire study population. Each data point represents a single eye. The regression line and equation are shown. After adjustment for age and sex, reduction in total GCL volume was associated with an increase in axial length $(P=0.048)$. 